\title{
The reasons of Organizational conflicts among doctors Working in Iben Sina Hospital
}

\author{
Abdel Hakim Saad El Sadig \\ Medical Technology Department Sirte University
}

\begin{abstract}
The aim of this study is to identify the causes of organizational conflict of the doctors who are working in Iben Sina Hospital, and their relationship to each of role ambiguity, organizational climate, hence this study to look into the causes of organizational conflict, and its relationship to the organizational study variables, financial and administrative, lack of technical and technological possibilities, not to participate in decision-making, resistance to change.

For this purpose a questionnaire was designed and I selected sample of 50 single out of a whole society of the study which is numbered 156 single, and the number of statistically analyzable questionnaire was 34 questionnaires.

The researcher has used the descriptive methodology, as it follows the surveying potential method in this study, the study included 4 hypotheses, the first hypotheses is:- There is no significant relationship between the financial and administrative considerations and organizational conflicts of the Doctors who are working in Iben Sina Hospital.

The study results showed there are practices, administrative and financial constraints represent restrictions on the freedom of the decisions taken by doctors in the care of their patients and thus increasing the threat to the independence of professional doctors.
\end{abstract}

Keywords: Organizational conflicts - Doctors - Hospital

\section{Introduction:}

There is no doubt that the rapidly changing technical sheer sophistication and intensity of competition taking place in the regulatory business organizations, at the present time, in some way led to the emergence of conflict which has received wide attention, the band demonstrated by taking it by many researchers, that conflict is expresses bad phenomenon that often infect, organizations in contrast, the researchers looked to the modern school of conflict that is inevitable in the various aspects of the life of the organization. There is also another team that sees conflict necessary, a product of social interaction between individual organizational conflicts knows where, as a social interaction patterns which arise from the conflict of interests of individuals or groups (Sahar and Fidab 2011). Conflict represents one of the important topics where Take it pioneers bad classic entrance often organizations or work groups, so you must get rid of it have been the pioneers of behavioral entrance of the view that it is a natural phenomenon and the inevitability accompany human interactions As pioneers of interactive view of the functional) (possible they looked to him Conflict as inevitable phenomenon should be managed and achieve the maximum benefit from it (Amal 2008). The behavior of the leadership and each type of them a different handle them and frustrating, and elusive, and their authoritarian, bureaucratic and democratic and, of course, there are managers help to the nature of work are working to provide an atmosphere comfortable work of their subordinates to their belief that if you worked on the palm of the employee it will produce and gives his best illusion often working on solving the problems of the staff and the comfort and there are also managers, unlike type I do not cause problems until they become a nuisance to their subordinates (Yahya 2011). There are various reasons for organizational conflicts that arise in various administrative regulations and these reasons, organizational reasons: style decisions to participate, and the multiplicity of administrative units in the organization, and the discrepancy in social centers for employees, and the lack of rationing and clear roles and tasks, and the discrepancy in the criteria used to evaluate the performance and determine bonuses, and multiple levels of management The correlation functions between the administrative units and staff and limited resources and material and technical potential and resistance to change, and there are personal reasons for conflicts, such as the style and nature of some of the characters and the varying cultural, social and educational backgrounds among the workers, and the lack of job satisfaction for different reasons (Tawfik 2008). Hence this study to look into the causes of organizational conflict, and its relationship to the organizational study variables, financial and administrative , lack of technical and technological possibilities, not to participate in decision-making, resistance to change. So as to achieve hospital goals in order to reach a set of solutions that will help in reducing the severity of struggled and avoid negative impacts and take advantage of 
its aspects, the turn of climate regulatory comfortable boosts the morale of workers and strengthens the work of the group and provides access to the highest levels of performance efficiency and effectiveness.

\section{The Research Problem:}

Reacts working in various administrative levels with each other on an ongoing basis in order to achieve the goals of the institution and lead this interaction to an agreement on some things and disagreement about some conflicts, and often leads incompatibilities and conflicts of interest to regulatory occurrence and health institutions is an exception in this regard, they are also experiencing such conflicts. So this study looking at the causes of organizational conflicts among workers in the Ibn Sina Teaching Hospital, and his relationship with some of the other financial and administrative possibilities, lack of technical and technological possibilities, not to participate in decision-making, resistance to change.

\section{The study questions:}

1. What is the impact of the financial and administrative considerations in the occurrence of organizational conflicts inside Iben Sina Hospital?

2. What is the impact of the lack of professional and technical capabilities in the occurrence of organizational conflicts inside Iben Sina Hospital?

3. What is the impact of non-participation in the decision-making in the occurrence of organizational conflicts inside Iben Sina Hospital?

4. What is the impact of resistance to change in the occurrence of organizational conflicts inside Iben Sina Hospital?

\section{The Research Objectives:}

1. To know the causes of organizational conflicts among workers in the Ibn Sina Hospital.

2. To provide some solutions and recommendations that will help decision makers in Iben Sina hospital in alleviating conflicts and deal with it and avoid its negative effects.

3. Benefit of researches in the field of organizational conflicts, especially in the field of the reasons of conflicts, and its relationship to the study variables.

\section{The Research Importance:}

The importance of study comes from the subject of great importance in the field of organizational behavior, organizational conflicts inside a hospital, where he, as long as there are individuals and debate in the work environment. It is clear that the importance of organizational conflicts strengthened through surveys and scientific research as one of the most important topics administrative practiced by managers as severe conflicts or continuous adversely affect the stability work and to the detriment of the performance of employees, and be a source of stress and anxiety as it affects the climate of internal environment of medical organizations, and leads to a lack of job satisfaction, especially as these organizations take care of the most expensive and the most precious thing in life to an individual health. The organizations conflict has received interest writers and researchers in the world, but did not find the same importance on the Arab level, in addition to the bulk of research on the subject of organizational conflicts focused on the side of management organizational conflicts and strategies and their relationship.

Therefore this study seeks to define causes and methods of dealing with it, also this study try to contribute to the reduction of the negative effects of the organizational conflicts found in hospitals.

\section{The Research Hypotheses:}

1. There is no significant relationship between the financial and administrative considerations and organizational conflicts in Iben Sina hospital.

2. There is no significant relationship between the artistic and the technical possibilities and organizational conflicts in Iben Sina hospital.

3. There is no significant relationship between the lack of participation in decision-making and conflicts in Iben Sina hospital.

4. There is no significant relationship between resistance to change and organizational conflicts in Iben Sina hospital. 


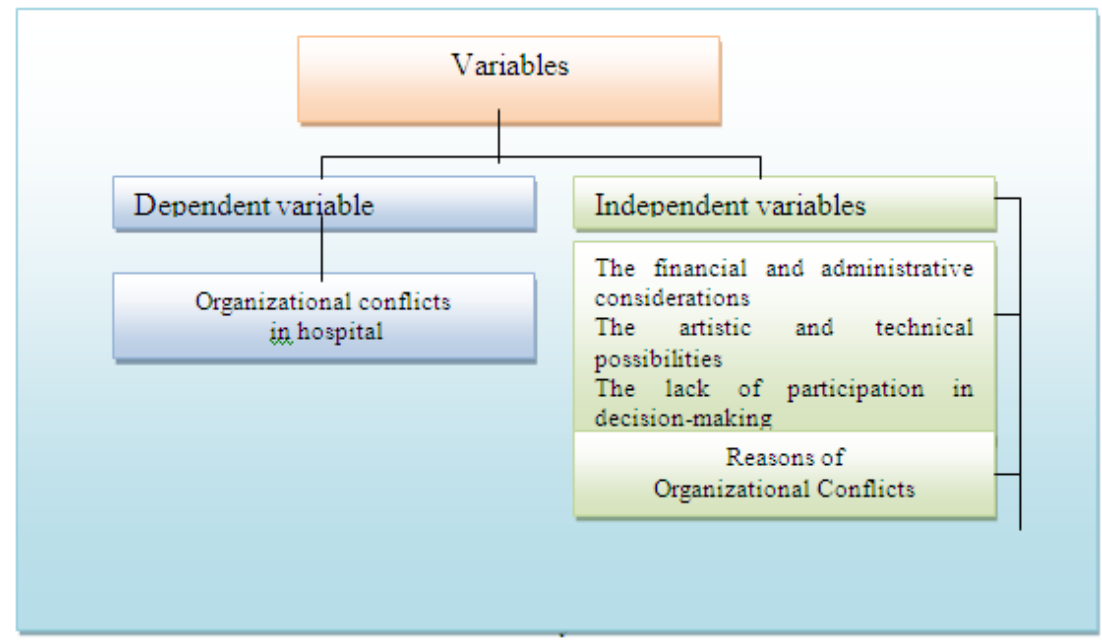

Model of study

\section{Privious Studies}

\section{Local studies:}

\section{Salah Omran Ferjany (2004)}

The factors determining the efficiency of the top management, Empirical Study of Arab cement company, and Libyan Cement Company. the problem of study that there is a palace administrative consideration by the top management of organizations direction of regulatory and conflicts that lead to the neglect of these conflicts and not addressed in an appropriate manner and and scientific manner commensurate seriousness and intensity as most members of senior management, especially the state-owned organizations look to the conflict only negative sense, leading to an increase in the negative conflicts, thereby hindering the performance and twice the efficiency of the organization in achieving its goals. Has been reached and the results were most important:

- The most important reasons are the causes of organizational conflict lies in the conflict and personal conflict within groups.

- The absence of effective communication system in the organizations under study, and especially between supervisors and subordinates that led to a personal conflict and the conflict between the groups.

- Did not get along with common goals for employees within the organization adequate attention by senior management.

\section{Mahmoud Ibrahim Khalifa Hmalh (2012)}

"Organizational conflict management and its relationship to job satisfaction, a field study on the General company for Water and Sanitation in Tripoli". Aims this study to conflict management related to job satisfaction of public company for water and sanitation in Tripoli, focusing on the most important causes of the complexity of relationships and the complexity of the organizational structure of organizational conflict and the ambiguity of roles. The study found a low level of effective control over the employee's performance, the lack of objective performance appraisal process and the absence of critical systems of reward and punishment, and the existence of ongoing disagreements between subordinates during the performance of their business and do not fit the wages and salaries charged by the employee play working and this causes the entanglement of relations within the company under study.

The reasons for the ambiguity of the role within the company due to:

- Lack of clarity of communication between superiors and subordinates, and the lack of clarity in how decisions are made, the lack of accurate job descriptions. And thus overlap in the terms of reference and functions within the company, as well as social conditions, cultural and political conditions in society which affect the employee's duties, and the lack of effective systems of incentives and rewards.

- On the complexity of organizational structures within the company, the most important reasons for this complexity are: the complexity of rules and laws and regulations, the lack of match between of the organizational structure in the units and the actual sections of existing and responsibilities and subject her contacts and between the current organizational structure of the lack of continuous development of the organizational structure, lack of understanding of the organizational structure of personnel management menu. 


\section{Arabic studies:}

\section{Fawzi Abdul Rahman Hamid Abu Askar (2008)}

"The conflict management styles and their impact on organizational development, An Empirical Study of the Palestinian Ministry of Health in the Gaza Strip", where the study aimed to identify the five conflict management styles (pattern of power and control, the pattern of cooperation, settlement pattern, pattern of avoidance, pattern waiver) and the extent of its application by management to resolve the conflict and what is the pattern in the Palestinian Ministry of Health and also aimed to determine the effect of these patterns on the three levels is the OD (individuals - working groups - regulation). The study was conducted on a stratified random sample of the various divisions of the staff of doctors - dentists - pharmacists - Nursing - technical professionals in addition to the category of administrators, and the total number of respondents (475) employees from 14 institutions (hospitals and primary care clinics) across the Gaza Strip, data was collected and information through a questionnaire and the researcher used the descriptive analytical method for conducting the study. The study found the following results:

Management uses the four styles in dealing with conflict and are arranged in descending order as follows: (style and power control, settlement pattern, pattern of avoidance, pattern waiver), but that the rate of use of the conflict, all the patterns are weak low ratios. The pattern is the fifth did not recognize him. As the sample organizational development at the level of individuals and groups and the organization careless application rate is very weak and unclear for employees.

\section{Hamid Tawfiq Hamid Tawalbeh (2008)}

"Impact of leadership on organizational conflict patterns in public administration institutions in Jordan" This study aimed to identify the impact of leadership on organizational conflict patterns in public administration institutions in Jordan, as the study aimed to identify leadership styles rule in most public institutions in Jordan and identify organizational conflict management used by managers in these institutions methods. The study found a range of results, including:

That the leadership styles of all kinds (authoritarian style, authoritarian style and goodness, and style consultant, and Co and transformational style) style had an impact on the organization and a clear conflict among managers in public institutions in Jordan Management.

It recommended the need to train managers on leadership styles and methods and actors in ending the conflict or minimize it especially good and authoritarian style in order to improve the leadership styles to the appropriate level and by which activation of organizational conflict management in public institutions in the process of Jordan.

\section{Foreign studies:}

Oraegbu Anthony .C.(2012)

"CONFLICT MANAGEMENT IN HEALTH CARE ORGANIZATIONS" (A protocol for a study in Umoru Shehu ultramodern hospital Maiduguri, Northeast Nigeria). The study seeks to explore the experience of the conflict as seen by hospital nurses in Tehran, Iran, Islamic Republic of Iran. Although the conflict control approach has been discussed widely in all parts of the world, are available on the perception of effective conflict resolutions between nurses and hospital in Iran any existing data on the research.

The study aimed to:

- Recognize nurses and reactions to the conflict.

- Organizational structure.

- Hospital management style and the conditions and the nature of the job assignment.

- Individual characteristics and understand the mutual interaction of the consequences of the conflict.

The study concluded

The nurses penalty not of the sources of conflict and should be strategies to resolve the conflict and understand the mutual interaction mode to be the main factor capable of preventing and resolving conflicts effectively and this approach will benefit the quality of patient care through a healthy work environment, and conflict reduces the efficiency of the nurses and the system of nursing as a whole, it We recommend that you take action to control it effectively.

The methods of data collection:

\section{Methodology}

\section{Secondary sources:}

It have been collected from Arabic and foreign Studies, books, articles, theses and previous research, and the information network (Internet). 


\section{Primary sources:}

Through a questionnaire that was designed for the purposes of testing hypotheses, which have been distributed to the Random sample to many doctors in the Iben Sina teaching hospital.

The researcher analyzed the data collected through the questionnaire and test hypotheses using the SPSS system for statistical analysis, and the use of statistical methods to measure the relationship between the variables of the study.

\section{The research Sample:}

The research sample was chosen randomly from the doctors. After the researcher distributed the questionnaire mentioned above, which were 50 questionnaires to doctors of Iben Sina hospital, recovered all 34 of them are valid for the study, and the researcher think it's enough to make judge on the hypotheses'.

\section{The questionnaire}

The Aspects of questionnaire form and the numbers of items:

Table 1

\begin{tabular}{|l|c||}
\hline \multicolumn{1}{|c|}{ Aspects } & No. of items \\
\hline \hline The financial and administrative considerations & 15 \\
\hline The artistic and the technical possibilities & 10 \\
\hline The decision-making. & 14 \\
\hline The resistance to change and organizational conflicts in hospitals. & 10 \\
\hline Total & 49 \\
\hline
\end{tabular}

All items could be responded to in one of Five ways:

Completely Agree - To some extent agree - Agree - Never agree - Not agree

To find a basis that we can use it to judge on the impact of each variable on the independent variable in our study.

\section{Procedures}

The researcher collected and processed the data by distribution the questionnaire to a research sample. He interviewed as many members of the sample as he could, to explain the aspects of the questionnaire to them.

\section{Scientific correlation of the questionnaire}

\section{Validity: (Content Validity)}

The researcher applied content validity by submitting the questionnaire during preparation and before application in the final form- to ten specialized experts (Validity judges) in the management and medical field.

\section{Reliability}

The test was performed and retaken a second time after an interval of 7 days to calculate the reliability of the questionnaire form. It was conducted on an exploratory study sample represented by 10 doctors, who were chosen randomly from outside the research sample. The correlation coefficient of the performances is (0.968), which indicates its reliability.

\section{Testing Hypothesis:}

After the implementing the scale to collect the variables data the researcher uses these data to test the hypothesis as follows:

\section{The 1st hypothesis:}

There is no significant relationship between the financial and administrative considerations and organizational conflicts in hospitals.

Table (2) Result Of The 1st Hypothesis

\begin{tabular}{|c|c|c|c|c|c|c|}
\hline & Std. Deviation & $\begin{array}{c}\text { Std. Error } \\
\text { Mean }\end{array}$ & $\mathrm{t}$ & $\mathrm{df}$ & $\begin{array}{c}\text { Sig } \\
\text { (2-tailed) }\end{array}$ & Differences \\
\hline 3.19 & 1.00536 & .16995 & -.1 .821 & 34 & .027 & significant \\
\hline
\end{tabular}

The result:

Illustrated in Table (2) that the t-test calculated value Sig. (2-tailed) of the significant level of the user (0.05), that any significant distinctions and the null hypothesis is rejected for the sample. 


\section{The 2st hypothesis:}

There is no significant relationship between the artistic and the technical possibilities and organizational conflicts in hospitals.

Table (3) Result Of The 2st Hypothesis

\begin{tabular}{|c|c|c|c|c|c|c|}
\hline & Std. Deviation & $\begin{array}{c}\text { Std. Error } \\
\text { Mean }\end{array}$ & $\mathrm{t}$ & $\mathrm{df}$ & $\begin{array}{c}\text { Sig } \\
\text { (2-tailed) }\end{array}$ & Differences \\
\hline 2.7 & .92411 & .15620 & -5.048 & 34 & .000 & significant \\
\hline
\end{tabular}

The result:

Based on the results table (3) The second hypothesis is rejected, as the significant differences, because the t-test calculated value Sig (2-taile) less than the significance level used (0.05).

\section{The 3st hypothesis:} in hospitals.

There is no significant relationship between the lack of participation in decision-making and conflicts

Table (4) Result Of The 3st Hypothesis

\begin{tabular}{|c|c|c|c|c|c|c|}
\hline Mean & Std. Deviation & $\begin{array}{l}\text { Std. Error } \\
\text { Mean }\end{array}$ & $\mathrm{t}$ & $\mathrm{df}$ & $\begin{array}{c}\text { Sig } \\
\text { (2-tailed) }\end{array}$ & Differences \\
\hline 2.96 & .93327 & .19897 & -2.696 & 34 & .011 & significant \\
\hline
\end{tabular}

The result:

We note that the calculated value of $t$ less than the significant level of the user (0.05) Therefore, we reject the null hypothesis and accept the alternative hypothesis.

The 4st hypothesis: hospitals.

There is no significant relationship between resistance to change and organizational conflicts in

Table (4) Result Of The 4st Hypothesis

\begin{tabular}{|c|c|c|c|c|c|c|}
\hline & Std. Deviation & $\begin{array}{c}\text { Std. Error } \\
\text { Mean }\end{array}$ & $\mathrm{t}$ & df & \multicolumn{2}{c|}{ Sig } \\
(2-tailed) & Differences \\
\hline 2.65 & .82966 & .17688 & -4.805 & 34 & .000 & significant \\
\hline
\end{tabular}

The result:

As a result of the test shows that the calculated value of $t$ less than the significant level of the user and the fourth hypothesis is rejected.

\section{Conclusion}

- Hospitals are significantly represented in the bureaucratic systems and laws, one of the reasons for the conflict.

- Practices, administrative and financial constraints represent restrictions on the freedom of the decisions taken by doctors in the care of their patients and thus increasing the threat to the independence of professional doctors.

- There constraints in administrative practices make the doctors, they can not use what they own knowledge and experience for the benefit of patients.

- The hospital can not provide the lack of professional and technical capabilities in the occurrence of organizational conflicts inside the hospital, also the right climate for the exchange of expertise and training and education, and the lack of harmony with the professional work environment, so occur the conflicts

- The decision-making authority in the hospital confined to leadership, and supervisory, and many doctors believed that the opportunity is available to them to participate, causing the conflicts among leadership and hospital staff.

- Organizational conflict often occurs in hospitals as a result of parking against some responsible leadership development and change as a result of attempts by the fear of failure, or a threat to their vested interests or fear of confusion prevailing organizational relationships. 
- The organization of administrative policies in hospitals, roads and decision-making powers in the various aspects of the technical and administrative work. In most cases the decision-making powers be limited to the occupants of the supervisory and leadership positions.

- They believed many of the members of the medical staff, the opportunity is not available to them to participate in the making of many influential on heuristic decisions in the hospital while some occupants managerial positions believed necessity of the separation between the two sides of medical and administrative which often raises some sort of organizational conflict between the two groups.

\section{References}

[1]. Abdul Aziz Mukhaimar, Mohammed Taamna "Recent trends in hospital management (concepts and applications)" The Arab Organization for Administrative Development Publications 2003

[2]. Abdul Karim Ibrahim Thuwaini "The impact of organizational culture on the development of human resources application to public institutions," Master Thesis submitted in the Faculty of Economics and Trade University, Malam Abdul Aziz. .2008.

[3]. Abu Salah Ali Hbda "conflict in organizations and its impact on job satisfaction," An Empirical Study on the administrative divisions of the General Company for Electricity district of Tripoli, a letter of introduction for a master's degree, Department of Administration and Management, School of Finance and Management Science, Academy of Graduate Studies, 2002.

[4]. Ahmed Yusuf Ahmed Aloah "organizational conflicts and their impact on job satisfaction," compared to the views of staff at the universities of Al-Azhar and Islamic study for a master's degree in business administration, the Islamic University of Gaza Graduate Studies, Faculty of Commerce, Department of Business Administration, 2008.

[5]. Amal Ali Mahmoud al-Obeidi, "organizational conflict strategy and the possibility of achieving the goals of the organization," Journal of Management and Economics Sixty-Ninth Issue 2008

[6]. Anita L. Tucker W. Scott Laura D. Janisse "Organizational Factors that Contribute to Operational Failures in Hospitals" working paper Hrvard Business school September 4, 2013 Turkey.

[7]. Fawzi Abdul Rahman Hamid Abu Askar "Conflict management styles and their impact on organizational development," An Empirical Study of the Palestinian Ministry of Health in the Gaza Strip, for a master's degree in Business Administration, Islamic University College of Commerce, Department of Business Administration, 2008 Gaza.

[8]. Imad Said Abu Zeid, "dealing with organizational conflicts between senior management and directors of middle management between managers and their impact on the efficiency of the regulatory process," An Empirical Study on the popular corner methods, study submitted within the high-leave requirements (MA), Department of Administration and Management, School of Business Administration and Finance Academy of Graduate Studies, the spring of 2006.

[9]. Jiri Beran, Petra Sumcovova; "Introduction to Medical Psychology(Doctor-Patient Communication)" Plzen 2004.

[10]. Khalid Abdullah Al-Rashidi Prican "The role of internal coalitions in reducing organizational conflicts of Kuwait Airways Corporation" study submitted to complete the requirements for obtaining a master's degree in Business Administration, Department of Business Administration, College of Business, University of the Middle East in 2012.

[11]. Mahmoud Ibrahim Khalifa Hmalh "Managing organizational conflict and its relationship to job satisfaction," An Empirical Study of the company operating water and sewage, a study submitted for the purpose of completing the requirements for obtaining high Masters degree in Business Administration, Department of Management and Organization, School of Business Administration and Finance, the Libyan Academy Tripoli - Libya, the spring of 2012.

[12]. Oraegbu Anthony .C. "CONFLICT MANAGEMENT IN HEALTH CARE ORGANIZATIONS" (A protocol for a study in Umoru Shehu ultramodern hospital Maiduguri, Northeast Nigeria). Master thesis in public Health, 2012

[13]. Rateb Al Saud, Zainab Shawabkeh "Resistance to change in educational organizations" working paper submitted to: Philadelphia 17th International Conference (culture change:-dimensional representations-factors), which is organized by the Faculty of Arts and the University of the Arts in Philadelphia 6 - 11/08/2012

[14]. Roohangiz Karimi, Zoharah Binti, Omar Farhad, and Alipour Zinab Karimi "THE INFLUENCE OF ROLE OVERLOAD, ROLE CONFLICT AND ROLE AMBIGUITY ON OCCUPATIONAL STRESS AMONG NURSES IN SELECTED IRANIAN HOSPITALS" International Journal of Asian Social Science, 2014

[15]. Sahar Obaid , FidabRateb "organizational reasons Alsara with doctors working in Rafidia Hospital" An-Najah National University Faculty of Economics and Administrative Sciences Department of Business Administration in 2011

[16]. Saleh Omran Ferjany "conflict management as one of the determinants of the efficiency of the organization's senior management," An Empirical Study of Saudi Cement Company and the Libyan Cement Company for the completion of the upper part of the holiday masters in management and organization requirements, School of Finance and Management Science, Academy of Graduate Studies, the spring of 2004.

[17]. Saud Al-Otaibi "Post subordinates helps to increase self-confidence and develop personal skills, and eliminates conflicts within organization "Administrative Development magazine published by the Department of Public Relations and Media at the Institute of Public Administration number 119. 2010 Saudi ArabiaArabia

[18]. Tawfik Hamid Tawalbeh "The impact of leadership styles to manage organizational conflict among managers," An Empirical Study on public institutions in Jordan provided to complete the requirements for a doctorate degree in the Business Administration, School of Finance and Banking, Arab Academy for Banking and Financial Sciences, 2008.

[19]. Yahya bin Musa bin Abdullah "Leadership styles and their relationship to organizational conflict administers the organizations own" Master Thesis - Virtual University Britain 2011 